\title{
Editorial: The Future of Coral Reefs Subject to Rapid Climate Change: Lessons From Natural Extreme Environments
}

\author{
Emma F. Camp ${ }^{1 *}$, Verena Schoepf ${ }^{2}$, Peter J. Mumby ${ }^{3}$ and David J. Suggett ${ }^{1}$ \\ ${ }^{1}$ Climate Change Cluster, University of Technology, Sydney, NSW, Australia, ${ }^{2}$ Oceans Graduate School, UWA Oceans \\ Institute and ARC Centre of Excellence for Coral Reef Studies, The University of Western Australia, Perth, WA, Australia, \\ ${ }^{3}$ Marine Spatial Ecology Lab, School of Biological Sciences, University of Queensland, St Lucia, QLD, Australia
}

Keywords: marginal, extreme, coral reefs, climate change, suboptimal

\section{Editorial on the Research Topic}

The Future of Coral Reefs Subject to Rapid Climate Change: Lessons From Natural Extreme Environments

Coral reefs globally have to contend with increasing environmental impacts and rapid climate change (Hoegh-Guldberg et al., 2014). Understanding if, and how, coral reefs and their associated biodiversity will persist is a central question for scientists, reef managers, and policy makers worldwide. An important emerging research area shaping our understanding of how coral reef ecosystems might adapt and/or acclimate to environmental and climate change, has been through the study of naturally extreme coral environments.

The 15 contributions assembled in this Research Topic consider corals and reef fishes persisting in marginal or extreme reef environments. The opening article of this Ebook is a review by Camp et al. that provides a global synthesis of 285 research articles. The review indicates clearly that corals, in particular, exhibit a great deal of plasticity in their realized niche, yet no single taxon appears consistently successful across extreme environments examined to date. Common survivorship traits expressed by corals within such extremes include phenotypic plasticity, maintenance of energy reserves (e.g., enhanced heterotrophy), and genetic diversity. However, the review highlight significant knowledge gaps in our understanding of the multitude of abiotic factors that affect the persistence of coral reefs, and identifies priorities for future research.

Thomas et al. also contributed a review article, targeting the mechanisms that facilitate coral survivorship within the back-reef pools of Ofu, American Samoa. This unique system in Ofu has generated a wealth of research, which has shown both acclimation and adaptation processes occurring to support coral survival under high temperatures. The authors conclude in their review that corals may, in fact, have the tools required to cope with future climate change through their genetic diversity, phenotypic plasticity, dispersal abilities, and prevalence across large temperature gradients. At what spatial scale these traits can support survival remains to be observed and will ultimately depend on other local interacting abiotic parameters. For example, Bahr et al. found that the duration and magnitude of high temperatures were the primary factors determining coral bleaching susceptibility at Kāne’ohe Bay, Hawaii. However, differing local irradiance, precipitation, and turbidity within the bay created spatial variation in bleaching prevalence.

Severe marine heatwaves are an increasingly conspicuous component of climate change that catastrophically impact coral reefs (Frölicher et al., 2018; Oliver et al., 2018). Elevated turbidity is considered suboptimal for coral growth, yet an abiotic factor that could aid corals' ability to survive 
marine heatwave events. Morgan et al. report higher coral bleaching tolerance of reef corals in nearshore, turbid waters along the Great Barrier Reef, Australia, during the 2015-2016 warming event. Only $1.5 \%$ of studied colonies showed partial bleaching, and coral cover after the warming event remained unchanged from pre-event measures. Their findings suggest that the increased ability of corals in turbid environments to attenuate solar irradiance that can otherwise compound thermal stress (a stressor's antagonism; Brown et al., 2013), may provide refuge for native corals. Furthermore, the high organic matter of turbid reefs can support elevated coral heterotrophy that can facilitate energy maintenance during periods of stress (Anthony and Fabricius, 2000). Van Woesik and Mccaffrey drew similar conclusions based on their study of corals on the Florida Reef Tract from 2005-2015, where they suggest under a warming ocean that corals capable of surviving in turbid waters will potentially be preferentially selected for.

For corals not living in turbid environments, protection during marine heatwaves events could be provided through local micro-refugia. Hoogenboom et al. report variation in bleaching susceptibility of Acropora spp. on the Great Barrier Reef during the 2015-2016 thermal stress event. Corals living in shaded microhabitats, created by the crevices and overhangs of the coral reef three-dimensional structure, experienced less coral bleaching due to reduced irradiance. These findings reinforce the importance of studying local abiotic conditions needed to inform and reconcile biological observations of patchiness of coral survival.

The tolerance of corals to temperature anomalies is not restricted to marine heatwave events, as corals can also be subjected to marine cold spells. Tuckett and Wernberg describe a marine cold spell event in 2016 off the coast of Perth, Western Australia that saw temperatures fall below $15.5^{\circ} \mathrm{C}$, and remain below $17^{\circ} \mathrm{C}$ for 19 days. Despite the extreme cool waters, native corals of these subtropical reefs showed minimal $(<5 \%)$ visual signs of bleaching. Whether exposed to extreme high or low temperatures, corals that are not protected through environmental refuge will be required to adapt and/or acclimate to the prevailing environmental conditions, or risk potential extirpation. Riegl et al. use the Persian Arabian Gulf (PAG) to explore the demographic mechanisms that can lead to winnowing of coral species poorly adapted to changing environmental conditions. They report variable species susceptibility to winnowing following environmental stress. Losses in coral cover, coral size, and population fecundity will be crucial in determining the future connectivity of a species population, and ultimately, whether it declines following environmental disturbances.

Fecundity, larvae settlement, and post-settlement processes are clearly important contributors to the ecological success of any coral species, particularly under environmental stress and climate change (Richmond et al., 2018). The ability of corals to recover from stress events will depend, in part, on their reproductive capacity and the availability of suitable substrate to colonize. What space remains available for coral recruitment depends on how other taxa have been impacted by the stress event (Mumby and Van Woesik, 2014), and which taxa colonize an environment first. Bento et al. investigated recruitment success of different taxa at three regions within north-east Arabia that experienced different environmental disturbances. Using unglazed terracotta tiles as an artificial substrate to study recruitment, they observed low coral recruitment, and high recruitment of non-coral taxa across the regional sites. Regional differences were reported in the initial recruiting taxa, which could be an important factor in determining the future colonization success of corals at these impacted reefs.

For corals to survive climate-induced stressors, such as ocean warming and acidification, may require migration into new habitats (Pandolfi and Kiessling, 2014). Lohr et al. investigated the ability for corals to recruit into seagrass meadows in the Cayman Islands. Seagrass habitats have been proposed as potential ocean acidification refugia due to their ability to offset the negative impacts associated with ocean acidification (Manzello et al., 2012). Fourteen coral taxa were able to recruit into the seagrass meadows investigated, with recruit populations comparable in composition to those established in the local seagrass meadows. Interestingly, some coral species abundant on the fringing back-reef were absent from the adjacent seagrass meadows. Further studies are required to understand the drivers that might prevent the recruitment of some species into the marginal seagrass habitat.

Increasing evidence of the ability of corals to tolerate environmental stress and survive in extreme environments suggests that all members of the coral holobiont (animal host, algal symbiont and associated microbes) are important. Grottoli et al. investigated the response of the coral holobiont to temperature stress in thermally tolerant corals from the northern Red Sea. Their findings demonstrated species-specific responses, but that maintenance of energy reserves and heterotrophic capacity appear to be important traits to support thermal tolerance. Hume et al. investigated algal symbionts of corals from the world's hottest sea to better understand the genetic diversity of the Symbiodinium thermophilum group that has been associated with native corals' thermal tolerance. Their findings reveal a genetic boundary (as small as $20 \mathrm{~km}$ ) structuring genetically distinct populations of $S$. thermophilum. While this may, in part, result from limited connectivity, the authors hypothesize that other factors are likely important in establishing local symbiont populations. The flexibility of corals to adjust their associated microbes when experiencing environmental change has been postulated as a major aid to coral survival (Torda et al., 2017). Rothig et al. report distinct microbiomes for the Red Sea deep coral Eguchipsammia fistula in situ compared to ex situ. In under a year, corals kept ex situ under increased oxygen and food availability experienced very different microbiomes compared to in situ populations. Corals exhibiting a flexible microbiome may therefore have greater phenotypic plasticity to persist across different environmental conditions.

While the majority of articles received as part of this Research Topic focused on corals, two articles considered the persistence of fishes in marginal reef environments. Shraim et al. studied the stomach content of fishes living in the southern Arabian Gulf where temperatures are extreme. They found Pomacanthus aquilus and $P$. trichrourus had seasonal variation in their diet 
that corresponded to changes in food availability. However, P. maculosus had a diet dominated by coral and sponge over both seasons. Such findings highlight the species- specific responses that will potentially occur for reef associated taxa as coral cover declines worldwide. Booth et al. also reported speciesspecific responses in the capacity of coral reef associated fishes to move into temperate waters of New South Wales, Australia. Their 18-years dataset revealed over 150 coral reef fish species recruiting to temperate reefs of Sydney (latitude $34^{\circ} \mathrm{S}$ ) and 60 species to Merimbula (latitude $37^{\circ} \mathrm{S}$ ). The ability of species to tolerate temperature drops during winter was found to be a good general indicator of predicting coral reef associated fishes range expansion. Habitat availability and local predators are also important considerations. More research into fishes and non-coral taxa of extreme and marginal systems is clearly an important area for future research.

As climate change alters reef landscapes globally, focused research into coral reef taxa persisting within suboptimal systems becomes increasingly important, as it can provide important insights into the biological mechanisms taxa require to survive. While no single suboptimal system provides a perfect analog to future reef conditions, investigations carried out in extreme environments can elucidate complex abiotic, ecological and biogeochemical processes inherent to reef systems.

\section{REFERENCES}

Anthony, K. R., and Fabricius, K. E. (2000). Shifting roles of heterotrophy and autotrophy in coral energetics under varying turbidity. J. Exp. Mar. Biol. Ecol. 252, 221-253. doi: 10.1016/S0022-0981(00)00237-9

Brown, C. J., Saunders, M. I., Possingham, H. P., and Richardson, A. J. (2013). Managing for interactions between local and global stressors of ecosystems. PLoS ONE 8:e65765. doi: 10.1371/journal.pone.0065765

Frölicher, T. L., Fischer, E. M., and Gruber, N. (2018). Marine heatwaves under global warming. Nature 560, 360-364. doi: 10.1038/s41586-018-0383-9

Hoegh-Guldberg, O. R., Cai, E. S., Poloczanska, P. G., Brewer, S., Sundby, K., et al. (2014). "The Ocean." in Fifth Assessment Report of the Intergovernmental Panel on Climate Change (IPCC). Cambridge; New York, NY: Cambridge University Press, 1655-1731.

Manzello, D. P., Enochs, I. C., Melo, N., Gledhill, D. K., and Johns, E. M. (2012). Ocean acidification refugia of the Florida Reef Tract. PLoS ONE 7:e41715. doi: 10.1371/journal.pone.0041715

Mumby, P. J., and Van Woesik, R. (2014). Consequences of ecological, evolutionary, and biogeochemical uncertainty on the response of coral reefs to climatic stress. Curr. Biol. 24, 413-423. doi: 10.1016/j.cub.2014.04.029

Oliver, E. C., Donat, M. G., Burrows, M. T., Moore, P. J., Smale, D. A., et al. (2018). Longer and more frequent marine heatwaves over the past century. Nat. Commun. 9:1324. doi: 10.1038/s41467-018-03732-9
The insights garnered can, in turn, shed important light on the potential responses of corals, coral reefs and associated organisms to a changing ocean environment. The papers collated in this Research Topic provide a renewed appreciation for the diversity of mechanisms coral reef taxa are able to utilize to survive in extreme and marginal reef environments and highlight the value of studying these underexplored ecosystems.

\section{AUTHOR CONTRIBUTIONS}

All authors listed have made a substantial, direct and intellectual contribution to the work, and approved it for publication.

\section{FUNDING}

The contribution of EC and DS to manuscript writing was through the Australian Research Council (ARC) Discovery grant DP160100271 to DS.

\section{ACKNOWLEDGMENTS}

We thank the Frontiers in Marine Science Editorial staff for their invitation and support in producing this Special Issue.

Pandolfi, J. M., and Kiessling, W. (2014). Gaining insights from past reefs to inform understanding of coral reef response to global climate change. Curr. Opin. Environ. Sustain. 7, 52-58. doi: 10.1016/j.cosust.2013. 11.020

Richmond, R. H., Tisthammer, K. H., and Spies, N. P. (2018). The Effects of Anthropogenic stressors on reproduction and recruitment of corals and reef organisms. Front. Mar. Sci. 5:226. doi: 10.3389/fmars.2018. 00226

Torda, G., Donelson, J. M., Aranda, M., Barshis, D. J., Bay, L., et al. (2017). Rapid adaptive responses to climate change in corals. Nat. Clim. Chang. 7, 627-636. doi: $10.1038 /$ nclimate 3374

Conflict of Interest Statement: The authors declare that the research was conducted in the absence of any commercial or financial relationships that could be construed as a potential conflict of interest.

Copyright (C) 2018 Camp, Schoepf, Mumby and Suggett. This is an open-access article distributed under the terms of the Creative Commons Attribution License (CC BY). The use, distribution or reproduction in other forums is permitted, provided the original author(s) and the copyright owner(s) are credited and that the original publication in this journal is cited, in accordance with accepted academic practice. No use, distribution or reproduction is permitted which does not comply with these terms. 